\section{Charles Dickens y su aporte a la medicina: en el bicentenario de su nacimiento}

\section{Charles Dickens and his contribution to medicine: a note to the bicentenary of his birth}

\section{Sr. Editor:}

Charles Dickens (1812-1870) (Figura 1) es uno de los escritores ingleses más importantes de la historia. Prolífico novelista y creador de personajes inolvidables (Oliver Twist, David Copperfield, etc), se caracterizó por un agudo poder de observación sumado a una capacidad sobresaliente para transcribir lúcidamente estas descripciones en sus escritos. No en vano, una editorial aparecida en el British Medical Journal en relación a su muerte, en 1870, expresó: "los médicos podemos decir: qué útil sería para la medicina tener una persona así, con tal poder de observación y capacidad descriptiva, y que entregara estas habilidades al arte de la medicina"2. Otros autores han dicho que si Dickens no hubiera sido escritor, podría haber sido un gran actor, un gran predicador, un gran político e incluso un gran médico ${ }^{3,4}$.

Las descripciones de Dickens, quién no tuvo ninguna formación médica, son muy vívidas y detallistas, lo que permite descubrir en varias de sus novelas condiciones médicas que hasta ese entonces no tenían un diagnóstico como tales. Destacan descripciones en el ámbito de la Medicina Interna, Neurología, Psiquiatría, Otorrinolaringología y Genética, entre otras especialidades ${ }^{3-6}$. Dickens sentía una especial afinidad por lo bizarro, también por lo que podría aparecer a veces grotesco e incluso horripilante a una persona no instruida. En el período victoriano, era común encontrar en la calle pacientes muy discapacitados en lo físico y mental, debido a la precariedad de los sistemas de salud de la época y que Dickens ayudó a cambiar. Dickens incluyó estas observaciones para lograr más realidad en sus relatos. Igualmente, obtuvo información de muchos médicos por haber estado aquejado de diversas patologías (gota, crisis isquémicas cerebrales, etc), incluyendo a 50 médicos en su producción literaria ${ }^{5}$. Muy crítico de la profesión médica, se burlaba de su ignorancia: en al menos dos obras puso en boca de sus personajes la frase "los médicos son en vano"3,5. En esta nota se mencionan sólo algunas de las tantas caracterizaciones médicas de Dickens.

La descripción médica más conocida de Dickens se da en "Los papeles póstumos del Club Pickwick" (1837). En esta novela, el personaje Joe -el "niño gordo"- ... padecía claramente apneas del sueño e hipersomnia asociadas a su obesidad, lo que fue llamado después "síndrome de Pickwick". Dickens describió: "Joe, el niño gordo, fluctuaba entre períodos de gran somnolencia y otros en que despertaba sólo para comer con gran gula"3.

Sabemos que en la actualidad este cuadro representa el síndrome de apnea obstructiva del sueño (SAOS), que ha tomado gran relevancia por su asociación a morbilidad cardiovascular, metabólica y neurológica.

Poco conocida es su descripción de la parálisis supranuclear progresiva (PSP), que es una forma muy agresiva de Parkinson ${ }^{5}$. La descripción de Dickens es muy anterior a la definición de Steele, Richardson y Olszewski, realizada en 1964. Dickens junto a su amigo Wilkie Collins escribieron " $\mathrm{El}$ perezoso viaje de dos aprendices holgazanes" (1857). El narrador describe a un anciano en un bar, con los ojos inmóviles, fijos, con una marcada retracción de los párpados, como si estuvieran clavados en la frente, un volumen de voz muy bajo, movimientos lentos, lo que sugiere bradicinesia, y una forma muy insegura de sentarse y caminar, que pueden expresar la inestabilidad postural propia de la PSP.

Dickens también describió la distonía, que son movimientos tipo torsión de segmentos del cuerpo. Así describió la forma común de distonía, que es la tortícolis, en la figura de Jeremías Flintwinch en "La Pequeña Dorrit" (1855-1857) (Figura 1b).

El intrigante Uriah Heep, en "David Copperfield" (1849-1850), exhibía con frecuencia movimientos de torsión del cuello y del tronco que se producían sobre todo cuando expresaba entusiasmo. Aunque no es posible definir retrospectivamente una entidad clínica, puede plantearse una distonía generalizada o corea. Dickens, en forma quizás un poco peyorativa, quiso resaltar estas extrañas manifestaciones para reflejar el carácter rayano en la maldad de Uriah. Así, Dickens lo hace aparecer como un individuo que hasta se mueve como una serpiente mortífera ${ }^{5}$.

El cobrador de deudas -el Sr. Pancks- en " $L a$ pequeña Dorrit", era un joven muy inquieto, producía con frecuencia vocalizaciones inapropiadas, que consistían en una voz inusualmente aguda o la emisión imprevista de gritos, pero también soplidos o carraspeos constantes. Muy notoria era en este personaje la obsesividad, reflejada 


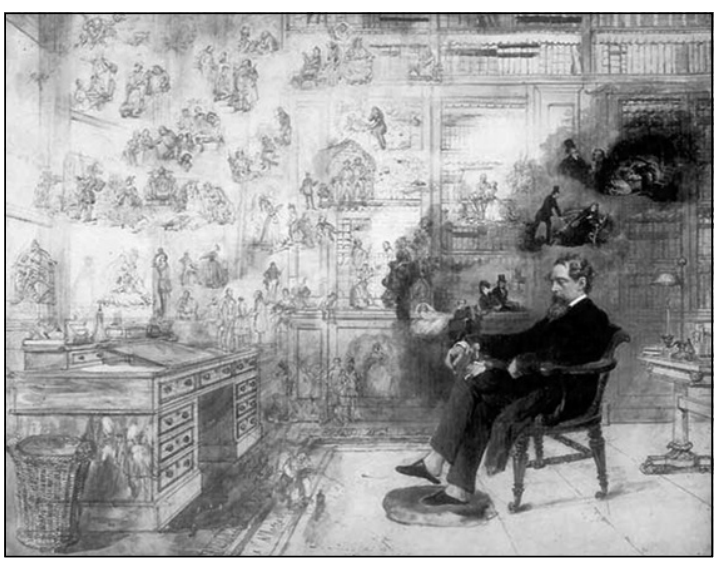

Figura 1a. Dickens en su biblioteca representado junto a algunos de sus múltiples personajes en su genial imaginación, retrato por Robert William Buss'.

por su escritura constante en un cuaderno, o su diligencia en la recolección de información acerca de los antecedentes de Dorrit. Se puede suponer que Dickens está describiendo el síndrome de Tourette 30 años antes de que lo definiera Gilles de la Tourette 5 . Éste consiste en la presencia de tics motores, como frecuentes pestañeos, muecas faciales, encogimiento de hombros, asociado a vocalizaciones diversas.

En la familia Smallweed, de "La Casa Desolada” (1852-1853), Dickens describió una rara condición hereditaria en que los miembros son de baja estatura, cognitivamente sanos pero envejecen prematuramente, lo que ha sugerido el diagnóstico de Progeria ${ }^{6}$.

Las diversas formas de epilepsia no estuvieron ajenas a los personajes de Dickens, incluso el status epilepticus. En "La Casa Desolada" describió en el personaje Guster, al servicio de los Snagsby "nunca se pasaba una noche tranquila en esa casa, ya que Guster todas las noches presenta convulsiones a veces una tras otra sin recuperarse cuando venía la siguiente"... ${ }^{4}$.

Además de estos aportes médicos de Dickens, a través de su obra se evidencia una gran crítica a las inequidades sociales en Inglaterra. Dickens apoyó los hospitales y refugios para los más desposeídos, especialmente los niños. Sin duda que, además de sus aportes como escritor, vemos que influyó en los cambios sociales en Inglaterra en el siglo XIX, que hicieron de ese país un mejor lugar para vivir, para los más desvalidos de la sociedad victoriana.

Dickens falleció a los 58 años, de una hemorra-

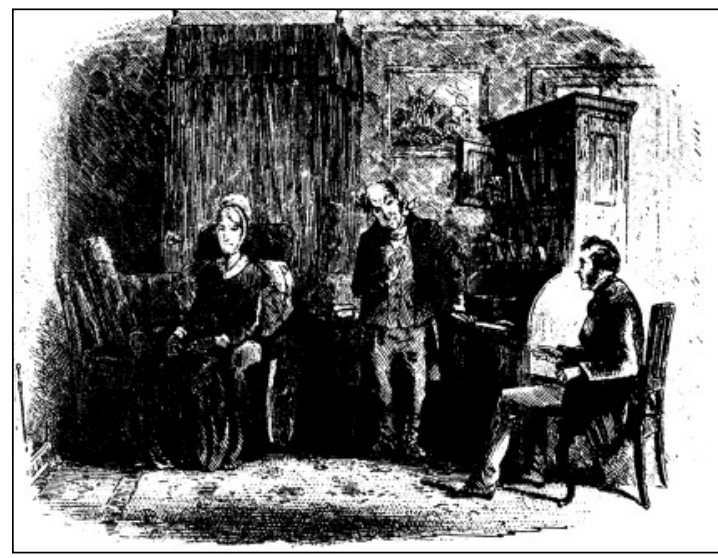

Figura 1b. El personaje Jeremías Flintwinch (en el centro) de "La pequeña Dorrit", evidenciando una torticolis con inclinación a derecha. Dibujo original de Phiz, pseudónimo de Hablot K. Browne, para la primera edición de la obra'.

gia cerebral. Se encuentra enterrado en la Abadía de Westminster, en Londres, en el Rincón de los Poetas.

Dickens nos dejó un extraordinario legado literario, con fascinantes personajes, pero además nos mostró que el Arte puede beneficiarse mucho de la Medicina.

Agradecimientos: A Osvaldo Gil, Bibliotecario de la Facultad de Medicina, Universidad de Chile, por aportar valiosas referencias.

Marcelo Miranda C. Departamento de Neurología, Clínica Las Condes. Santiago de Chile.

\section{Referencias}

1. http://en.wikipedia.org/wiki/Charles_Dickens- Visitado 31 de marzo de 2012.

2. Obituary. BMJ 1870; 1: 636.

3. Brain R. Dickensian diagnosis. BMJ 1955; ii: 1553-6.

4. Cosnett JE. Charles Dickens and Epilepsy. Epilepsia 1994; 35: 903-5.

5. Schoffer K, O'Sullivan J. Charles Dickens: The man, medicine and movement disorders. J Clin Neurosc 2006; 13: 898-901.

6. Singh V. Description of a family with Progeria by Charles Dickens. Neurology 2010; 75 (6): 571.

Correspondencia a:

Dr. Marcelo Miranda. Fono: 6104608

E-mail:marcelomirandac@gmail.com 